\title{
Relationship between resilience, depression, stress and anxiety among nurses in a tertiary health institution in Nigeria.
}

\author{
*Olabisi O.I. ${ }^{1}$, Taiwo Dosumu T. ${ }^{1}$, Oyewumi Z.O. ${ }^{2}$, Adegoke J.I. ${ }^{3}$, Oladotun N.O. ${ }^{2}$, \\ Aremu E.0. ${ }^{3}$
}

\begin{abstract}
Background: This study determines the relationship between resilience, depression, stress and anxiety among professional nurses who are frontline workers.

Methodology: The study was conducted among nurses working in Lagos State University Teaching Hospital (LASUTH) Ikeja, Lagos State. The Connor-Davidson Resilience scale and Depression, Anxiety and Stress questionnaire administered to 360 nurses. Simple frequency, mean, standard deviation and Pearson correlation were used for the analysis.

Results: The majority (90\%) of the respondents was female and about two thirds of them were married. Overall summarized scores for the level of anxiety, depression and stress were $46.6 \%, 38.5 \%$ and $37.7 \%$ respectively. Resilience had statistically significant positive correlation with years of experience $(\mathrm{r}=0.160, \mathrm{p}=0.002)$; negatively significant with stress $(\mathrm{r}=-0.281, \mathrm{p}<0.001)$ and negatively significant with anxiety $(r=-0.210, p<0.001)$. Depression was negatively significant with years of experience $(r=-$ $0.132, \mathrm{p}=0.013)$ while stress was positively significant with depression $(\mathrm{r}=0.764, \mathrm{p}<0.001)$ and anxiety $(\mathrm{r}=0.751, \mathrm{p}<0.001)$.
\end{abstract}

Conclusion: There is a need to organize programmes that will improve the resilience of professional nurses should be organized to reduce the effects of stress, anxiety and depression among nurses.

Keywords: Resilience, Nurses, depression, stress, anxiety

\author{
*Corresponding author \\ Olabisi O.I. \\ ORCID-NO: http://orcid.org/0000-0002-6388-7847 \\ Email: seyiolabisi55@gmail.com \\ ${ }^{1}$ Department of Nursing Science, Bowen University, Iwo \\ ${ }^{2}$ Ladoke Akintola University of Technology Open and Distance Learning Centre, Ogbomoso; \\ ${ }^{3}$ Fountain University, Osogbo
}




\title{
Relation entre la résilience, la dépression, le stress et l'anxiété chez les infirmières d'un établissement de santé tertiaire au Nigéria
}

\author{
*Olabisi O.I. ${ }^{1}$, Taiwo Dosumu T. ${ }^{1}$, Oyewumi Z.O. ${ }^{2}$, Adegoke J.I. ${ }^{3}$, Oladotun N.O. ${ }^{2}$, \\ Aremu E.O. ${ }^{3}$
}

Résumé

Contexte général de l'étude : Cette étude détermine la relation entre la résilience, la dépression, le stress et l'anxiété chez les infirmières professionnelles qui sont des travailleurs de première ligne.

Méthode de l'étude: L'étude a été menée auprès d'infirmières travaillant au Lagos State University Teaching Hospital (LASUTH) Ikeja, Lagos State. Échelle de résilience Connor-Davidson et questionnaire sur la dépression, l'anxiété et le stress administrés à 360 infirmières. La fréquence simple, la moyenne, l'écart type et la corrélation de Pearson ont été utilisés pour l'analyse.

Résultat de l'étude : La majorité $(90 \%)$ des répondants était des femmes et environ les deux tiers d'entre eux étaient mariés. Les scores globaux résumés pour le niveau d'anxiété, de dépression et de stress étaient respectivement de $46,6 \%, 38,5 \%$ et $37,7 \%$. La résilience avait une corrélation positive statistiquement significative avec les années d'expérience $(\mathrm{r}=0,160, \mathrm{p}=0,002)$; négativement significatif avec le stress $(\mathrm{r}=$ $-0,281, p<0,001)$ et négativement significatif avec l'anxiété $(r=-0,210, p<0,001)$. La dépression était négativement significative avec les années d'expérience $(r=-0,132, p=0,013)$ tandis que le stress était positivement significatif avec la dépression $(r=0,764, \mathrm{p}<0,001)$ et l'anxiété $(\mathrm{r}=0,751, \mathrm{p}<0,001)$.

Conclusion : Il y a un besoin d'organiser des programmes qui amélioreront la résilience des infirmières professionnelles devraient être organisés pour réduire les effets du stress, de l'anxiété et de la dépression chez les infirmières.

Mots-clés : Résilience, infirmières, dépression, stress, anxiété

\author{
*Corresponding author \\ Olabisi O.I. \\ ORCID-NO: http://orcid.org/0000-0002-6388-7847 \\ Email: seyiolabisi55@gmail.com \\ 'Department of Nursing Science, Bowen University, Iwo \\ ${ }^{2}$ Ladoke Akintola University of Technology Open and Distance Learning Centre, Ogbomoso; \\ ${ }^{3}$ Fountain University, Osogbo
}




\section{INTRODUCTION}

Professional nurses are subjected to high a level of psychological distress including stress, anxiety and depression in a healthcare setting $(1,2)$. Workload, inpatient aggression, shortage of nurses, death and dying, bullying, violence, lack of required equipment for procedure, rotating shift work, unhealthy communication between nurses and other health care professionals are some of the contributors to high levels of occupation stress in the work place (3-5).

Previous studies have shown that workrelated stress may have a profound effects on nurses' quality of life, turnover intention and ultimately the quality of care rendered to patients $(1,6,7)$. Burnout and workplace bullying among nurses have also been reported to result in high level of depression, anxiety and stress among practicing nurses (8-10). A study in India revealed that nurses experienced a high level of depression and anxiety and the level was high among the less experienced nurses (11).

Resources in coping with stress, depression and anxiety in clinical setting are very important for nurses to improve their wellbeing and prevent attendant negative effects. One of the personal resources for coping with symptoms of mental illness is resilience. Resilience has become an increasingly studied concept in nursing profession because of its importance in reducing the negative consequences of stress and other negative effects of work environment (12). Resilience is the tendency to positively adjust, cope and adapt to the workplace challenges and build a personal strength (12). Professional resilience skills are required for nurses to succeed in the nursing profession and to sustain adverse and challenging work environment (13).

A study in a developed country showed that resilience reduced the level of occupational stress among nurses (14). A quasi-experimental study in Iran indicated that resilience (15). However, studies on the relationship between resilience, depression, stress and anxiety among nurses in Nigeria are scanty. This study is intended to assess the mediating role of resilience on the level of stress, depression and anxiety experienced by the nurses.

\section{METHODS AND MATERIALS Sampling size determination and procedure}

The study was conducted among nurses working in Lagos State University Teaching Hospital (LASUTH) Ikeja, Lagos State. The hospital serves as a training institution for undergraduates and postgraduate' clinical trainees. It also serves as a referral center from different secondary health institutions around Lagos State. Cross sectional descriptive research design was utilized for the study. The total population of nurses working in the institution at the time of conducting the study was 810 and a sample of 360 nurses was considered for the study after calculation using Yamane formula (9) $: \mathrm{n}=\mathrm{N} / 1+\mathrm{N}(\mathrm{e})^{2}$; where $\mathrm{n}=$ Number of samples, $\mathrm{N}=$ Total population $=810, \mathrm{e}=$ Error tolerance 0.05 and $10 \%$ attrition rate. The questionnaires were administered to the nurses using a convenient sampling method due to the different work shifts of the nurses which made it difficult to perform probability sampling. Lagos State University Teaching Hospital's research committee granted approval to conduct the study among nurses. The respondents' consent was taken after the objectives and procedures of the study were explained to them. They were given the questionnaires thereafter and were requested to fill the questionnaire and submit it to the nurse in charge of each ward in a sealed envelope to ensure privacy.

\section{Study Instrument}

The Connor-Davidson Resilience Scale 10(CD-RISC 10) and Depression, Anxiety and Stress (DASS-21) questionnaire were used to collect data from the respondents. The depression, anxiety and stress scale questionnaire (DASS-21) (16) was used to assess the level of depression, anxiety and stress. DASS is a 21 items scale consisting of three subscales with seven items each rated on 4 point Likert scale and the total score range from 0 - 42. Depression score was classified as normal (0 -9), mild (10 -13), moderate (14-20), severe (21-27) and extremely severe (28 and above). Anxiety score was classified as normal (0-7), mild (8-9), moderate (10-14), severe (15-19) and extremely severe (20 and above). Stress was classified as normal (0$14)$, mild (15-18), moderate (19-25), severe (2633 ) and extremely severe (34 and above). Studies in Nigeria have shown that the DASS-21 has overall good-to-excellent internal consistency among pregnant women (16) and family members of patients admitted in the intensive care unit in Nigeria (17). The Connor-Davidson Resilience Scale 10 developed by Connor and Davison (18) was used to assess the level of resilience among the nurses. It is a brief version of 25-item CD-RISC and the score range from 0 40. Respondents' rate items on a 5-point Likert scale, ranging from 0 (not true at all) to 4 (true nearly all the time). Total scores are calculated by 
summing all 10 items. A higher score indicates higher resilience. The reliability and validity of the instrument has been ascertain to be strong among nursing students in Nigeria (18).

\section{Data Analysis}

The data collected were analyzed using the Statistical Package for the Social Sciences (SPSS 21.0 for Windows). Descriptive analyses including frequency and percentages, means and standard deviations were used to describe the socio-demographic characteristics of the respondents and the level of depression, anxiety, stress and resilience of the respondents. Pearson correlation was used to determine the relationship among the depression, anxiety, stress, age, years of experience and resilience.

\section{RESULTS}

The findings of the study as indicated in table 1 reveals that the majority $324(90 \%)$ of the respondents were females while about two thirds of them were married. Half of them had a first degree in Nursing Science, and a few of them $32(8.9 \%)$ had a postgraduate certificate. According to table 2, 46.6\% ( mild = 18.3; moderate $=13.3 ;$ severe $=14.7), 38.5 \%($ mild $=$ 10.8 ; moderate $=16.4$; severe $=6.1$; extremely severe $=4.4)$ and $37.7 \%($ mild $=19.7$; moderate $=$ 14.4; severe $=3.3$; extremely severe $=1.1$ ) were anxious, depressed and stressed respectively. Resilience level of the respondents was high (Mean $=28.55$, Standard deviation $=8.74)$. Resilience was statistically significant positive correlation with years of experience $(\mathrm{r}=0.160$, $\mathrm{p}=0.002$ ); statistically significant negatively correlation with stress $(r=-0.281, p<0.001)$ and statistically significant negatively correlated with anxiety $(\mathrm{r}=-0.210, \mathrm{p}<0.001)$. Depression is statistically significant negatively correlated with years of experience $(r=-0.132, p=0.013)$. Stress is statistically significant positively correlated with depression $(\mathrm{r}=0.764, \mathrm{p}<0.001)$ and anxiety $(\mathrm{r}=0.751, \mathrm{p}<0.001)($ table 3$)$.

\section{DISCUSSION}

The aim of this study was to determine the correlations among resilience, depression, stress and anxiety. The result of this study showed that resilience is statistically significant negatively correlated with stress. In other words, the higher the resilience, the lesser the stress experienced by nurses. Resilience is one of the mediating factors capable of reducing the effect of stress on an individual. This finding is consistent with the results of the study conducted to assess the relationship between resilience and occupational stress among nurses (19) and faculty members in Iran medical schools (14).

The result of this finding further indicated that stress was positively significant with depression and anxiety but is contrary to a previous study which revealed that work-related stress was negatively associated with depression and anxiety (1). Professional nurses working in the hospital according to this finding are stressed, depressed and anxious which is in line with many works of the literature that nurses experienced high level of stress, depression and anxiety in their workplaces and are associated with different factors including poor working environment and increase level of workplace violence $(7,20)$. The result of the study further suggested that nurses' resilience increases with years of experience and the level of nurses' resilience negatively influenced the anxiety level. This is similar with the study on the relationship between resilience and anxiety among nurses who opined that higher resilience predicted the lower level of anxiety and depression (19). Younger nurses do experience higher levels of anxiety and depression because they are less experienced in dealing with different problems in a clinical setting and also have lower resilience $(11,21)$.

\section{CONCLUSION}

Our study showed that nurses experience a high level of anxiety, stress and depression as well as that resilience of nurses' increases with age; the higher the level of resilience reduced the level of perceived stress and anxiety experienced by nurses. Lastly, nurses who are stressed experienced a higher level of depression and anxiety. There is a need to organize programmes such as in-service training and continuing education that will improve the resilience of professional nurses to reduce the effects of stress, anxiety and depression on nurses. The strength of this study is the use of standardize instrument to measure various concept. However, advanced inferential statistics would have been employed to further strengthen the findings.

\section{REFERENCES}

1. Poursadeghiyan M, Abbasi M, Mehri A, Hami M. Relationship Between Job Stress and Anxiety , Depression and Job Satisfaction in Nurses in Iran. The Social Sciences, 2016;11(9):2349-55.

2. Jordan TR, Khubchandani J, Wiblishauser M. The Impact of Perceived Stress and Coping Adequacy on the Health of Nurses? A Pilot Investigation. Nurs Res Pract, 2016;5(2)

3. Faremi F, Olatubi M, Adeniyi K, Salau O. 
Assessment of occupational related stress among nurses in two selected hospitals in a city southwestern Nigeria. Int $\mathrm{J}$ Africa Nurs Sci. $2019 ; 10(2): 68-73$. Av a i 1 a ble from:https://doi.org/10.1016/j.ijans.2019.01.00 8

4. Olabisi OI, Afolayan J, Oriola O, Ogunlade A, Olawoore S. Psychiatric nurses perspectives on causes and management of aggression in a Nigerian psychiatric hospital. AU J Heal Sci Biomed Res, 2019;1(1): 3-7

5. Olabisi OI, Ajibade BL, Ajao O, Ejidokun A, Oriola O. Experience and Attitude of Psychiatric Nurses toward Inpatient Aggression in a Nigerian Psychiatric Hospital. Int J Caring Sci. 2019;12(3):1547-60. Available from: http://ezproxy.umgc.edu/login?url=https://searc h.ebscohost.com/login.aspx?direct $=$ true $\& \mathrm{db}=\mathrm{cc}$ $\mathrm{m} \& \mathrm{AN}=139544928 \&$ site $=$ eds-live $\&$ scope $=$ site

6. Johnston D, Ph D, Bell C, Sc M, Jones M, Ph D, et al. Stressors, Appraisal of Stressors, Experienced Stress and Cardiac Response? A Real-Time , Real-Life Investigation of Work Stress in Nurses. Ann Behav Med, 2016;10(5):187-97.

7. Mohite N, Shinde M, Gulavani A. Occupational Stress among Nurses Working At Selected Tertiary Care Hospitals. International Journal of Science and Research 2014;3(6):999-1005.

8. Mousavi SV, Ramezani M, Salehi I, Hossein AA. The Relationship between Burnout Dimensions and Psychological Symptoms ( Depression, Anxiety and Stress ) Among Nurses. J Holist Nurs Midwifery, 2017;27(2):37-43.

9. Olabisi OI, Ajiboye T, Azeez F, Ejidokun A, Yusuff J. Workplace Bullying and Mental Health of Clinical Nuses in a Federal Medical Hospital in Southwest, Nigeria. LAUTECH J Nurs. 2021; 8(1):53-60

10. Akmal H, Halim M, Halim FW, Khairuddin R. Does Personality Influence Workplace Bullying and Lead to Depression Among Nurses. Psychology; 2019;53(2):3-12.

11. Shajan A, Nisha C. Anxiety and Depression among nurses working in a tertiary care hospital in South India.International Journal of Advances in Medicine, 2019; 6(5):1611-1615

12. Lin $\mathrm{C}$, Liang $\mathrm{H}$, Han $\mathrm{C}$, Chen $\mathrm{L}$, Hsieh $\mathrm{C}$. Professional resilience among nurses working in an overcrowded emergency department in Taiwan. Int Emerg Nurs. 2019;42(10):44-50. A v a i 1 a b 1 e f r o m : https://doi.org/10.1016/j.ienj.2018.05.005

13. Brennan EJ. Towards resilience and wellbeing in nurses. Br J Nurs. 2017;26(1).

14. Obeidavi A, Elahi N, Saberipour B. Relationship between resilience and occupational stress among the faculty members of Ahvaz Jundishapur University of Medical Sciences. Int J Biomed Public Heal. 2018;1(3):136-40.

15. Jafarizadeh $H$. Effect of resilience-based intervention on occupational stress among nurses.International Health Affair, 2017;15(9):159-63.

16. Olabisi OI, Dosumu T, Ademuyiwa G, Adeleke J, Nathaniel O, Olabisi T. Depression, Anxiety, Stress and Social Support Among Pregnant Women Attending Antenatal Clinic in a Nigerian Teaching Hospital. Bayero J Nurs Heal Care. 2020;2(2).

17. Olabisi OI, Olorunfemi O, Bolaji A, Azeez FO, Olabisi TE, Azeez O. Depression, anxiety, stress and coping strategies among family members of patients admitted in intensive care unit in Nigeria. Int J Africa Nurs Sci. 2020;13 Available

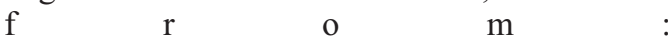
https://doi.org/10.1016/j.ijans.2020.100223

18. Aloba O, Olabisi O, Aloba T. The 10-Item Connor-Davidson Resilience Scale: Factorial Structure, Reliability, Validity, and Correlates Among Student Nurses in Southwestern Nigeria. J Am Psychiatr Nurses Assoc. 2016;22(1):43-51.

19. Hjemdal O, Vogel PA, Solem S, Hagen K, Stiles TC. The relationship between resilience and levels of anxiety, depression, and obsessivecompulsive symptoms in adolescents. Clin Psychol Psychother. 2011;18(4):314-21.

20. Maharaj S, Lees T, Lal S. Prevalence and Risk Factors of Depression, Anxiety, and Stress in a Cohort of Australian Nurses.Int. J. Environ. Res. Public Health 2019; 16(1)

21. Roberts NJ, Mcaloney-kocaman K, Lippiett K, Ray E, Welch L, Kelly C. Levels of resilience, anxiety and depression in nurses working in respiratory clinical areas during the COVID pandemic. Respir Med. 2020;176. Available from: https://doi.org/10.1016/j.rmed.2020. 106219 
Table 1: Sociodemographic characteristics of the respondents

\begin{tabular}{llll}
\hline Variable & Characteristics & Frequency & Percentage \\
\hline Sex & Male & 36 & 10 \\
Marital Status & Female & 324 & 90 \\
& Single & 112 & 31.1 \\
Highest level of & Married & 248 & 68.9 \\
education & Less than degree & 148 & 41.1 \\
& First Degree & 180 & 50.0 \\
Ward & Postgraduate & 32 & 8.9 \\
& Psychiatric ward & 16 & 4.4 \\
& Medical ward & 130 & 36.1 \\
& Intensive Care Unit & 52 & 14.4 \\
& Surgical ward & 70 & 19.4 \\
& Pediatrics & 16 & 4.4 \\
& Accident \&Emergency & 12 & 3.3 \\
& Obstetrics' and & 40 & 11.1 \\
& gynecology ward & & 6.7
\end{tabular}

Age $\quad$ Mean $=36.24 ; \mathrm{SD}=8.37 ;$ Range $=36 ;$ Minimum $=20 ;$ Maximum $=56$ Years of Experience $\quad$ Mean $=8.98 ; \mathrm{SD}=6.75 ;$ Range $=29 ;$ Minimum $=1 ;$ Maximum $=30$

Table 2: Level of stress, anxiety and depression among the respondents

\begin{tabular}{lllllll}
\hline \multirow{2}{*}{ LEVEL } & \multicolumn{2}{l}{ STRESS } & \multicolumn{2}{l}{ ANXIETY } & \multicolumn{2}{l}{ DEPRESSION } \\
\cline { 2 - 7 } & $\mathrm{F}$ & $\%$ & $\mathrm{~F}$ & $\%$ & $\mathrm{~F}$ & $\%$ \\
\hline Normal & 221 & 61.4 & 193 & 53.6 & 224 & 62.2 \\
Mild & 71 & 19.7 & 66 & 18.3 & 39 & 10.8 \\
Moderate & 52 & 14.4 & 48 & 13.3 & 59 & 16.4 \\
Severe & 12 & 3.3 & 53 & 14.7 & 22 & 6.1 \\
Extremely & 4 & 1.1 & NIL & NIL & 16 & 4.4 \\
severe & \multicolumn{7}{l}{ Range $=40 ;$ Mean $=28.55 ;$ SD $=8.74$} \\
\hline Resilience & \multicolumn{9}{l}{} \\
\hline
\end{tabular}


Table 3: Correlation among resilience, depression, anxiety, stress, age and years of experience among the respondents

\begin{tabular}{|c|c|c|c|c|c|c|c|}
\hline & & Age & $\begin{array}{l}\text { Years of } \\
\text { experience }\end{array}$ & Stress & Anxiety & Depression & Resilience \\
\hline \multirow[t]{3}{*}{ Age } & Correlation & 1 & $0.700 * *$ & -0.059 & -0.042 & -0.48 & 0.088 \\
\hline & Sig.2 (-tailed) & & 0.000 & 0.267 & 0.431 & 0.365 & 0.100 \\
\hline & $\mathrm{N}$ & 360 & 360 & 360 & 360 & 360 & 360 \\
\hline \multirow{3}{*}{$\begin{array}{l}\text { Years of } \\
\text { experience }\end{array}$} & Correlation & & 1 & -0.060 & -0.60 & $-0.132 *$ & $0.160 * *$ \\
\hline & Sig.2(tailed) & & & 0.261 & 0.256 & 0.013 & 0.002 \\
\hline & $\mathrm{N}$ & & 360 & 360 & 360 & 360 & 360 \\
\hline \multirow[t]{3}{*}{ Stress } & Correlation & & & 1 & $0.751^{* *}$ & $0.764 * *$ & $-0.281 * *$ \\
\hline & Sig.2 (tailed) & & & & 0.000 & 0.000 & 0.000 \\
\hline & $\mathrm{N}$ & & & 360 & 360 & 360 & 360 \\
\hline \multirow[t]{3}{*}{ Anxiety } & Correlation & & & & 1 & $0.745 * *$ & -0.199 \\
\hline & Sig.2 (tailed) & & & & & 0.000 & 0.000 \\
\hline & $\mathrm{N}$ & & & & 360 & 360 & 360 \\
\hline \multirow[t]{3}{*}{ Depression } & Correlation & & & & & 1 & $-0.210 * *$ \\
\hline & Sig.2 (tailed) & & & & & & 0.000 \\
\hline & $\mathrm{N}$ & & & & & 360 & 360 \\
\hline \multirow[t]{3}{*}{ Resilience } & Correlation & & & & & & 1 \\
\hline & Sig.2 (tailed) & & & & & & \\
\hline & $\mathrm{N}$ & & & & & & 360 \\
\hline
\end{tabular}

$* *$. Correlation is significant at the 0.01 level (2-tailed).

*. Correlation is significant at the 0.05 level (2-tailed). 